\title{
Estimating the lithospheric flexure of a plate with non-uniform flexural rigidity: a quantitative modelling approach
}

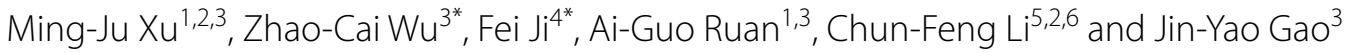

\begin{abstract}
Lithospheric deformation is a fundamental process in plate tectonics. It is, therefore, critical to determine how the lithosphere responds to geological loads to better understand tectonic processes. The lithosphere can be modelled as the flexure of a thin, elastic plate over long-term $\left(>10^{5} \mathrm{yr}\right)$ geological timescales. The partial differential equation for the flexure of an orthotropic plate is used indirectly to calculate theoretical admittance and coherence, which are then compared against the observed admittance and coherence to invert for the non-uniform flexural rigidity (or effective elastic thickness, $T_{e}$ ) of the plate. However, the process for accurately recovering variable lithospheric flexure remains unresolved, as the classical lithospheric model may overestimate the deflection of the plate. Here we adopt the classic lithospheric model with applied external and internal loads at the surface and Moho, respectively, and assume that the compensation material is denser than the mantle material beneath the Moho. The lithospheric flexure errors are derived mainly from the $T_{e}$ and Moho recovery errors in this lithospheric model. Synthetic modelling is then performed to analyse the influence of the $T_{e}$ and Moho errors. The analysis of synthetic modelling shows that: (1) the $T_{e}$ error-induced flexure errors exhibit a rippling pattern, and the rippling pattern is broader in high $T_{e}$ regions; (2) the Moho error-induced flexure errors mainly occur in the low $T_{e}$ regions, and applying Airy isostasy theory in low $T_{e}$ regions may still greatly overestimate the lithospheric deformation amplitude; and (3) the lithospheric flexure errors are dominated by the $T_{e}$ and Moho errors in the high and low $T_{e}$ regions, respectively.
\end{abstract}

Keywords: Loading of the earth, Effective elastic thickness, Lithospheric flexure, Error analysis

\section{Introduction}

Our understanding of the mechanics of the Earth's crust and lithosphere have been greatly advanced since the 1970s, via numerous modelling, including experimental examinations of the behaviour of physical bodies (e.g., Dorman and Lewis 1970, 1972; Lewis and Dorman 1970a, b) and derivations of the mathematics that describe lithospheric processes (e.g., McNutt 1980; Forsyth 1985; Burov and Diament 1992; Banks et al. 2001; Braitenberg

\footnotetext{
*Correspondence: wuzc@sio.org.cn; jifeii@163.com

${ }^{3}$ Key Laboratory of Submarine Geosciences, SOA \& Second Institute

of Oceanography, MNR, No.36 Baochubei Road, Hangzhou 310012, China

${ }^{4}$ National Institute of Natural Hazards, MEMA, No.1 Anningzhuang Road,

Beijing 100085, China

Full list of author information is available at the end of the article
}

et al. 2002; McKenzie 2003; Kirby and Swain 2009; Zhang et al. 2018a, b, c; Zhang et al. 2019a). These studies followed the principle that the lithosphere can be idealised if the main structural features are considered, thereby allowing simplified models to capture the key structures and geodynamics of the lithosphere. However, no information on the internal structure of the lithosphere has been used in these investigations, and its mechanical properties, such as the flexure of the tectonic plates, may be incorrectly estimated (Ribe 1982).

The lithospheric strength of tectonic plates reflects their resistance to vertical deformation in response to geological loads over long-term $\left(>10^{5} \mathrm{yr}\right)$ geological timescales (Watts and Burov 2003). This assumption allows the lithosphere to be modelled as the flexure of 
a thin, elastic plate via the partial differential equation for the flexure of an orthotropic plate (Timoshenko and Woinowsky-Krieger 1959). This equation is usually used indirectly to calculate theoretical admittance and coherence, which are then compared against observed ones to invert for the non-uniform flexural rigidity (or effective elastic thickness, $T_{e}$ ) of the plate (Kirby 2014). Numerous studies have used $T_{e}$ to analyse lithospheric rheology and deformation (Pérez-Gussinyé et al. 2009; Chen et al. 2015; Ji et al. 2017, 2020; Lu et al. 2020). However, this idealised term does not refer to an existing thickness or physical layer within the Earth, but instead corresponds to the thickness of an ideal elastic plate that undergoes the same deformation as the lithosphere under the same loads (Watts 2001). As $T_{e}$ is a periphrastical parameter for understanding lithospheric rheology and deformation, directly modelling lithospheric flexure should provide key insights into the nature of tectonic evolution and dynamics.

Here we use the classic lithospheric model with applied external and internal loads at the surface and Moho, respectively, and assume that the compensation material is denser than the mantle material beneath the Moho (Fig. 1). The density contrast between the compensation material and mantle material beneath the Moho is set to $200 \mathrm{~kg} / \mathrm{m}^{3}$, based on the density contrast between the uppermost and basal lithospheric mantle (Kaban et al. 2016). Notably, in some special areas, loads may be taken from specific geological attributes instead of topographies. In the subduction zones, for instance, slab pull may be considered as the main loads and usually be handled as boundary loading (e.g., Zhang et al. 2014, 2021), applying the corresponding plate flexure models has made a great deal achievements (e.g., Zhang et al. 2018a, b, c; 2019a, b). Taking the topographies, however, as the loads has a widespread application in estimating plate flexure and should have a wider prospect. The model used in this study is still an idealised model that considers the vertical density variation in the lithosphere. Furthermore, we obtain $T_{e}$ variations via the fan wavelet coherence method (Kirby and Swain 2004, 2008) and the Moho topography via a constrained gravity inversion method (Wu et al. 2017). Based on the finite-difference (FD) method shown by Kirby and Swain (2008), we reformat the equations to invert the lithospheric flexure of a two-layer lithospheric model. The errors associated with the lithospheric flexure estimation in such a lithospheric model are mainly derived from the $T_{e}$ and Moho errors. Synthetic modelling is then performed to analyse the influence of the $T_{e}$ and Moho errors on the lithospheric flexure estimation.

\section{Methodology}

The key to calculating lithospheric flexure via the FD method is to obtain accurate spatial distributions of the Moho and $T_{e}$. The Moho depth is usually recovered via gravity inversion (Wu et al. 2017). There are currently two main methods for mapping the spatial variations in $T_{e}$ based on the coherence between the Bouguer gravity anomaly (BGA) and topography/bathymetry. One is the multitaper method (McKenzie and Fairhead 1997; Pérez-Gussinyé et al. 2004), and the other is fan wavelet coherence method (Kirby and Swain 2004, 2008). The characteristic flexural wavelength is correlated with the strength of the lithosphere, and the flexural amplitude varies with both $T_{e}$ and the magnitude of the load (Watts 2001). These variations make it difficult to choose the multitaper window size to recover $T_{e}$. Signals of features

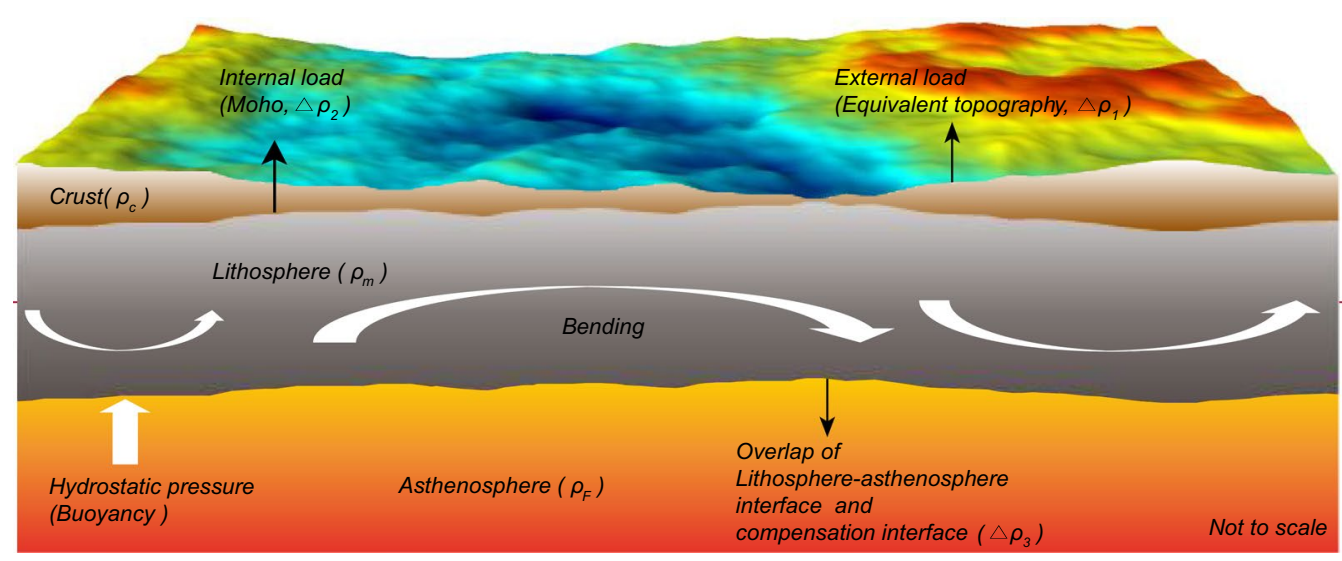

Fig. 1 Conceptual mechanical model of the lithosphere and asthenosphere, the compensation depth is set to be at the Lithosphereasthenosphere interface (LAI). $\rho_{C_{1}} \rho_{m}$ and $\rho_{F}$ are density values (Table 1), and $\Delta \rho_{1}=\rho_{c}-\rho_{f}, \Delta \rho_{2}=\rho_{m}-\rho_{c}, \Delta \rho_{3}=\rho_{F}-\rho_{m}$ are interface density contrasts, $\rho_{f}$ represents either the air density on land or seawater density in the ocean (revised from Banks et al. 2001) 
on a stronger lithosphere can be truncated when the selected window size is too small, resulting in an artificially low $T_{e}$. Conversely, $T_{e}$ can be blended across multiple features, with a potential bias toward the largest feature in the window, when the selected window size is too large (Pérez-Gussinyé et al. 2004, 2008; Kalnins and Watts 2009). The fan wavelet coherence method can alleviate these issues by allowing the $T_{e}$ features to be located at different wavelengths, and is employed to estimate $T_{e}$ in this study.

\section{Gravity inversion for Moho topography}

Joint inversions that involve gravity measurements and other geophysical constraints are generally employed to reduce the non-uniqueness of the best-fit models (Chappell and Kusznir 2008; Bai et al. 2014; Ji et al. 2018). Here we perform a three-dimensional gravity inversion that is constrained by seismic observations (Wu et al. 2017) to recover an accurate Moho topography. The Moho topography that corresponds to the complete Bouguer gravity anomaly can be expressed as $h(\mathbf{r})=h_{e}(\mathbf{r})+\Delta h(\mathbf{r})$, where $h_{e}(\boldsymbol{r})$ is the initial interface. The difference between the Moho and initial interface can then be obtained by substituting this difference into the gravity inversion equation (Oldenburg 1974):
(Oldenburg 1974) after the Moho topography is recovered. The detailed process is as follows: (1) linearly fit the Moho depth values and the corresponding Bouguer gravity anomalies with the constraint points; (2) then, use the fitting parameters to form the initial Moho grid $h_{e}(r)$ with the observed Bouguer gravity anomaly grid; (3) perform the iterative algorithm of Eq. (1); (4) the final Moho topography is obtained iteratively until the interface difference between adjacent iteration steps meets the error threshold, which is set to be $0.001 \mathrm{~km}$ in this study.

\section{Thin plate flexure}

For quick reference, we provide the key equations for estimating thin plate flexure, which can be easily calculated via the approach of Kirby and Swain (2008). We consider an elastic slab model that involves only the initial external (at the surface) and internal (at the Moho) loads, which are represented as $\left[\left(\rho_{c}-\rho_{f}\right) g h_{i}\right]$ and $\left[\left(\rho_{m}-\rho_{c}\right) g w_{i}\right]$, respectively. As the plate model is a linear system, the deflection can be divided into four components. The deflection of amplitude $w_{T}$ at the Moho and $h_{T}$ at the surface caused by the initial external load, $w_{B}$ at the Moho and $h_{B}$ at the surface caused by the initial internal load. Then, the final Moho topography after flexure is

$$
w=w_{T}+w_{B}
$$

$$
F[\Delta h(\mathbf{r})]=-\frac{F[\Delta g]}{2 \pi \varsigma \rho} e^{\mathbf{k} z_{0}}-\sum_{n=2}^{\infty} \frac{\mathbf{k}^{n-1}}{n !} F\left[\left\{h_{e}(\mathbf{r})+\Delta h(\mathbf{r})\right\}^{n}\right]-F\left[h_{e}(\mathbf{r})\right]
$$

where $F[]$ is the Fourier transform, $\Delta g$ is the complete Bouguer gravity anomaly, $\varsigma$ is Newton's gravitational constant, $\rho$ is the density contrast across the interface, $\boldsymbol{k}$ is the wave vector of the transformed function, $r$ is the entire $\mathrm{x}-\mathrm{y}$ plane and $z_{0}$ is the reference depth of the density interface, $n$ is the iterations, whose value depends on the convergence rate of Eq. (1) and the error threshold.

We largely follow the procedure outlined in $\mathrm{Wu}$ et al. (2017), except for the implementation of Eq. (1) to determine the interface difference during each iteration of the inversion, to ensure that both the Moho depth and Bouguer gravity anomaly satisfy the inversion equation and the final surface topography after flexure is

$$
h=h_{T}+h_{B} .
$$

The final deflection amplitude $v$ can then be expressed as

$$
v=h-h_{i}=w-w_{i}
$$

The relations of initial loads and deflection amplitude in the partial differential equation for flexure of an orthotropic plate are given by Timoshenko and WoinowskyKrieger (1959):

$$
-\left(\frac{\partial^{2} M_{x}}{\partial x^{2}}-2 \frac{\partial^{2} M_{x y}}{\partial x \partial y}+\frac{\partial^{2} M_{y}}{\partial y^{2}}\right)+\left(\rho_{m}-\rho_{f}\right) g v=-\left(\rho_{c}-\rho_{f}\right) g h_{i}-\left(\rho_{m}-\rho_{c}\right) g w_{i},
$$


where the bending and twisting moments are

$$
\left\{\begin{array}{l}
M_{x}=-D\left(\frac{\partial^{2} v}{\partial x^{2}}+\sigma \frac{\partial^{2} v}{\partial y^{2}}\right) \\
M_{y}=-D\left(\sigma \frac{\partial^{2} v}{\partial x^{2}}+\frac{\partial^{2} v}{\partial y^{2}}\right) \\
M_{x y}=-M_{x y}=-D(1-\sigma) \frac{\partial^{2} v}{\partial x \partial y}
\end{array}\right.
$$

and where $D$ is the flexural rigidity, $\sigma$ is Poisson's ratio. Furthermore, substituting the initial loads with Eq. (4), and simplifying Eq. (5) with the Laplace operator that gives (Timoshenko \& Woinowsky-Krieger 1959; Stark et al. 2003):
The main advantages of this model are:

1. The overestimated deflection of the lithosphere predicted via linear theory can be suppressed;

2. The density of the mantle usually increases with depth, so the model fits real data better in the framework of lithospheric-scale deflection;

3. The main inversion function (Eq. (6)) in such a model can be converted to Eq. (7), which can be considered as a forward equation with a small Winkler foundation, thereby ensuring that stable calculation results are always obtainable.

$$
\begin{aligned}
& D \nabla \nabla v+2 \frac{\partial D}{\partial x} \frac{\partial}{\partial x} \nabla v+2 \frac{\partial D}{\partial y} \frac{\partial}{\partial y} \nabla v+\nabla D \nabla v-(1-\sigma) \cdot\left\{\frac{\partial^{2} D}{\partial x^{2}} \frac{\partial^{2} v}{\partial y^{2}}-2 \frac{\partial^{2} D}{\partial x \partial y} \frac{\partial^{2} v}{\partial x \partial y}+\frac{\partial^{2} D}{\partial y^{2}} \frac{\partial^{2} v}{\partial x^{2}}\right\} \\
& =-\left(\rho_{c}-\rho_{f}\right) g h-\left(\rho_{m}-\rho_{c}\right) g w
\end{aligned}
$$

where all variables are functions of the $(\mathrm{x}, \mathrm{y})$ position, $\Delta=\left(\partial^{2} / \partial x^{2}\right)+\left(\partial^{2} / \partial y^{2}\right)$ is the Laplace operator. The minus sign on the right side of Eq. (6) demonstrates the plate acts as resistance to the topographic deformation. When $D$ reaches zero, Eq. (6) follows the Airy isostatic theory. The solution to Eq. (6) via the FD method is shown in Appendix A.

\section{A larger Winkler foundation}

A foundation that acts with a force proportional to the deflection at every point is known as a Winkler foundation (e.g., Huang and Thambiratnam 2001; Mofid and Noroozi 2009). An elastic foundation is usually expressed as $\rho_{m} g v$ in linear elastic plate theory. However, the deflection predicted via linear theory is always too high; this non-linearity decreases with increasing plate thickness, such that plates with $T_{e}>20 \mathrm{~km}$ are only slightly nonlinear (Ribe 1982). This overestimated deflection should be suppressed in ocean settings since $T_{e}$ is generally low in these settings. Here we use a two-layer model (Fig. 1), whereby the internal load is confined to the Moho, such that the entire lithosphere is modelled with a lithospheric elastic foundation with higher density $\left(\rho_{F}\right)$ than that of the uppermost layer of the mantle $\left(\rho_{m}\right)$. Equation (6) is then changed to

$$
\begin{aligned}
& D \nabla \nabla v+2 \frac{\partial D}{\partial x} \frac{\partial}{\partial x} \nabla v+2 \frac{\partial D}{\partial y} \frac{\partial}{\partial y} \nabla v+\nabla D \nabla v-(1-\sigma) \cdot\left\{\frac{\partial^{2} D}{\partial x^{2}} \frac{\partial^{2} v}{\partial y^{2}}-2 \frac{\partial^{2} D}{\partial x \partial y} \frac{\partial^{2} v}{\partial x \partial y}+\frac{\partial^{2} D}{\partial y^{2}} \frac{\partial^{2} v}{\partial x^{2}}\right\} \\
& +\left(\rho_{F}-\rho_{m}\right) g v=-\left(\rho_{c}-\rho_{f}\right) g h-\left(\rho_{m}-\rho_{c}\right) g w .
\end{aligned}
$$

\section{Fan wavelet coherency method}

The wavelet method for calculating the coherence between the topography and gravity data was first proposed by Stark et al. (2003), who employed a Gaussian window function as the transform kernel to estimate $T_{e}$ in southern Africa. The continuous wavelet transform offers the ability to obtain the local phase and amplitude of the topography and gravity anomalies, whereas the Fourier transform requires wavenumber averaging of the spectral estimates. The Gaussian wavelet fails to reproduce the Fourier power spectrum exactly (Kirby 2005). Two-dimensional Morlet wavelets, which are Gaussian-modulated complex exponential functions, can reproduce the Fourier spectrum (Kirby and Swain 2004). The spatial resolution of $T_{e}$ can be improved by adjusting the central wavenumber of the Morlet wavelet (Kirby and Swain 2011). Only the square of the real component of the wavelet coherence needs to be employed to estimate $T_{e}$ (Kirby and Swain 2008, 2009). The coherency, which is formed by obtaining auto- and cross-spectra at a series of azimuths over the $0^{\circ}-180^{\circ}$ range in a 'fan' and then averaging them (Kirby and Swain 2009), is computed as the real and positive coherence, which suffers from the problem of 
information loss. The squared real coherency can be expressed as a function of scale $s$ and position $\boldsymbol{x}$ :

$$
\gamma_{o b s}^{2}(s, \boldsymbol{x})=\frac{\left|\operatorname{Re}\left\langle B_{s x \theta} H_{s x \theta}^{*}\right\rangle_{180}\right|^{2}}{\left\langle B_{s x \theta} B_{s x \theta}^{*}\right\rangle_{180}\left\langle H_{s x \theta} H_{s x \theta}^{*}\right\rangle_{180}},
$$

where $B_{s x \theta}$ and $H_{s x \theta}$ represent the complex wavelet coefficients of the Bouguer gravity anomaly and topography, respectively, the * indicates complex conjugation, and the angular brackets denote azimuthal averaging performed over the entire $180^{\circ}$ azimuthal range. The continuous wavelet transform (CWT) is performed through the following equations:

$$
\left\{\begin{array}{l}
\left.\tilde{g}(s, \boldsymbol{x}, \theta)=F^{-1}\{\widehat{g}(\boldsymbol{k})) \widehat{\psi}_{s, \theta}^{*}(\boldsymbol{k})\right\} \\
\widehat{\psi}_{s, \theta}(\boldsymbol{k})=s \widehat{\psi}\left(s \Omega^{-1}(\theta) \boldsymbol{k}\right) \\
\widehat{\psi}(\boldsymbol{k})=e^{-\left[\left(u-\left|k_{0}\right| \cos \theta\right)^{2}+\left(v-\left|k_{0}\right| \sin \theta\right)^{2}\right] / 2}
\end{array} .\right.
$$

Here, $\widetilde{g}(s, \boldsymbol{x}, \theta)$ are the resulting 'wavelet coefficients', $F^{-1}$ is the inverse 2D Fourier transform, $\widehat{g}(\boldsymbol{k})$ is the 2D Fourier transform of a $2 \mathrm{D}$ spatially distributed signal $g(\boldsymbol{x}), \boldsymbol{k}=(u, v)$ is the $2 \mathrm{D}$ wavenumber, $\widehat{\psi}(\boldsymbol{k})$ is the $2 \mathrm{D}$ Fourier transform of the 2D Morlet wavelet, scale $s$ is also the dilation parameter, the "central wavenumber" $\left|k_{0}\right|=\pi \sqrt{2 / \ln 2} \approx 5.336$ is used in this study. Note that $v$ only represents the frequency domain coordinate parameter in Eq. (9), but elsewhere in this article is the flexure.
Table 1 Symbols and employed values for the model constants (revised from Kirby and Swain 2008)

\begin{tabular}{llll}
\hline Constant & Symbol & Value & Units \\
\hline $\begin{array}{l}\text { Young's modulus } \\
\text { Newtonian }\end{array}$ & $E$ & 100 & $\mathrm{GPa}$ \\
gravitational constant & $S$ & $6.67259 \times 10^{-11}$ & $\mathrm{~m}^{3} \mathrm{~kg}^{-1} \mathrm{~s}^{-2}$ \\
$\begin{array}{l}\text { Poisson's ratio } \\
\text { Acceleration due to }\end{array}$ & $\sigma$ & 0.25 & \\
gravity & $g$ & 9.80 & \\
$\begin{array}{l}\text { Mean Moho depth } \\
\text { Mean LAl depth }\end{array}$ & $z_{m}$ & 40 & $\mathrm{~m} \mathrm{~s}^{-2}$ \\
$\begin{array}{l}\text { Crustal density } \\
\text { Mantle density }\end{array}$ & $\rho_{c}$ & 120 & $\mathrm{~km}$ \\
Compensation & $\rho_{m}$ & 3200 & $\mathrm{~km}^{-3}$ \\
Mantle density & $\rho_{F}$ & 3400 & $\mathrm{~kg} \mathrm{~m}^{-3}$ \\
& & & $\mathrm{~kg} \mathrm{~m}^{-3}$ \\
\end{tabular}

Flexural components in Eqs. (2) and (3) can be replaced with equations including initial internal and external loads $w_{i}$ and $h_{i}$. As these two equations are linear, they form the so-called "load-deconvolution equations" in the wavenumber domain with the assumption that $T_{e}$ is uniform (Forsyth 1985; Kirby and Swain 2008). Following the formulation in Kirby and Swain (2011) and making the equations available for a two-layer model that

$$
\left(\begin{array}{c}
G \\
H
\end{array}\right)=\left(\begin{array}{cc}
\mu_{B} & \mu_{T} \\
\kappa_{B} & \kappa_{T}
\end{array}\right)\left(\begin{array}{c}
W_{i} \\
H_{i}
\end{array}\right)
$$

The parameters are

$$
\left\{\begin{array}{l}
\kappa_{B}=-\Delta \rho_{2} / \phi \\
\kappa_{T}=1-\Delta \rho_{1} / \phi \\
\mu_{B}=2 \pi \varsigma \Delta \rho_{2}\left(1-\Delta \rho_{2} / \phi\right) e^{-|\mathbf{k}| Z_{m}}-2 \pi \varsigma \Delta \rho_{3} e^{-|\mathbf{k}| Z_{F}} \Delta \rho_{2} / \phi \\
\mu_{T}=2 \pi \varsigma \Delta \rho_{2}\left(1-\Delta \rho_{1} / \phi\right) e^{-|\mathbf{k}| Z_{m}}-2 \pi \varsigma \Delta \rho_{3} e^{-|\mathbf{k}| Z_{F}} \Delta \rho_{1} / \phi \\
\phi=D|\mathbf{k}|^{4} / g+\left(\rho_{F}-\rho_{f}\right) \\
\Delta \rho_{1}=\rho_{c}-\rho_{f} \\
\Delta \rho_{2}=\rho_{m}-\rho_{c} \\
\Delta \rho_{3}=\rho_{F}-\rho_{m} \\
D=\frac{E T_{e}^{3}}{12\left(1-\sigma^{2}\right)}
\end{array},\right.
$$


where $G, \mathrm{H}$ mean the observed Bouguer gravity anomaly and surface topography, $|\mathbf{k}|=\left|k_{0}\right| / s$ is the equivalent Fourier wavenumber, $Z_{m}$ is the Moho depth, $Z_{F}$ is the LAI depth, $\varsigma, E$ and $\sigma$ are constant values (Table 1 ).

After Eq. (10) is solved, initial loads and flexural components can be obtained. Then, the predicted wavelet coherency is

$$
\Gamma_{p}^{(G)}(|\mathbf{k}|)=\frac{\left\langle G_{T} H_{T}^{*}+G_{B} H_{B}^{*}\right\rangle_{|k|}}{\left\langle G_{T} G_{T}^{*}+G_{B} G_{B}^{*}\right\rangle_{|k|}^{1 / 2}\left\langle H_{T} H_{T}^{*}+H_{B} H_{B}^{*}\right\rangle_{|k|}^{1 / 2}},
$$

where $T$ is for surface load components, and $B$ for subsurface load components. With the advantage of averaging being performed over the wavelet azimuth in the wavelet method, Eq. (12) can be further expressed as

$$
\Gamma_{p}^{(W T)}(s, \mathbf{x})=\frac{\mu_{T} \kappa_{T}\left\langle\left|\tilde{h}_{i}\right|^{2}\right\rangle_{180}+\mu_{B} \kappa_{B}\left\langle\left|\tilde{w}_{i}\right|^{2}\right\rangle_{180}}{\left[\mu_{T}^{2}\left\langle\left|\tilde{h}_{i}\right|^{2}\right\rangle_{180}+\mu_{B}^{2}\left\langle\left|\tilde{w}_{i}\right|^{2}\right\rangle_{180}\right]^{1 / 2}\left[\kappa_{T}^{2}\left\langle\left|\tilde{h}_{i}\right|^{2}\right\rangle_{180}+\kappa_{B}^{2}\left\langle\left|\tilde{w}_{i}\right|^{2}\right\rangle_{180}\right]^{1 / 2}},
$$

(e.g., Sclater \& Christie 1980; Ji et al. 2020), such that this random fractal initial load $\left(h_{i}\right)$ and flexure $(v)$ derived topography $(h)$ can be used in the synthetic modelling. The influences of both the recovered $T_{e}$ errors and inverted Moho errors on the FD-derived lithospheric flexure are investigated to determine how these inputs shape the model results.

\section{Model generation}

We follow the synthetic modelling procedure of Macario et al. (1995), and use the mid-point displacement method (Peitgen and Saupe 1988) to generate two-dimensional fractal Brownian surfaces that represent the initial external (surface, $h_{i}$ ) and internal (subsurface, $w_{i}$ ) loads. In addition, the $T_{e}$ model is also obtained by applying the where $\left\langle\left|\tilde{h}_{i}(s, \mathbf{x})\right|^{2}\right\rangle_{180}$ and $\left\langle\left|\tilde{w}_{i}(s, \mathbf{x})\right|^{2}\right\rangle_{180}$ mean the azimuthal averaged wavelet coefficients of initial surface and subsurface loads. By considering each local wavelet spectrum to be independent of adjacent spectra (the "decoupling" assumption), the wavelet coherency can be applied to approximately invert for local $T_{e}$ (Stark et al. 2003; Kirby and Swain 2004). Then the final $T_{e}$ distributions are obtained by finding the $T_{e}$ that provides the minimum misfit between the observed and predicted coherencies at each grid point, using Brent's method of 1-D minimization (e.g., Press et al. 1992).

\section{Synthetic modelling}

Synthetic modelling is commonly used to test the accuracy of the wavelet method (Stark et al. 2003; Kirby and Swain 2004, 2008). Random fractal initial loads and $T_{e}$ models are used as inputs to the flexural equation, which outputs the final surface topography $(h)$ and Moho topography $(w)$. We follow the same approach in our synthetic modelling. We employ Eq. (6) in the inversion since it is a thorough rearrangement of the flexural equation (Eq. (11)) in Kirby and Swain (2009) where the inputs are the final topography $(h)$ and a random fractal initial internal load $\left(w_{i}\right)$.

The equivalent topography, $T_{e}$ and Moho topography, are required to estimate lithospheric flexure. The equivalent topography can be specifically calculated using a global elevation model, sediment thickness model and sediment thickness-density conversion formula

mid-point displacement method, as Kirby and Swain (2008) noted: "fractal $T_{e}$ distributions are likely to be closer to the real Earth's $T_{e}$ structure." A fractal dimension of 2.5 is used for the surface (Fig. 2a) and subsurface loads (Fig. 2b), as well as the $T_{e}$ model (Fig. 2c). The grids consist of $255 \times 255$ points at a $20-\mathrm{km}$ spacing and are scaled to possess a realistic amplitude. Furthermore, the $T_{e}$ grid is low-pass filtered with a cutoff wavelength of $150 \mathrm{~km}$. We choose a central wavenumber of 5.336 in the subsequent fan wavelet coherence inversion since we place greater importance on the $T_{e}$ accuracy than its spatial resolution. We do not set a constant $F$ (loading ratio), as in Kirby and Swain (2008). Although this approach may go against Forsyth's fourth assumption about the proportionality of the power spectral densities of the initial loads (Forsyth 1985; Simons and Olhede 2013), the feasibility of the $T_{e}$ inversion with multiple varying $F$ interfaces via the fan wavelet coherence method has already been tested by Kirby and Swain (2009). The topography (Fig. 2d), Moho (Fig. 2e) and lithospheric flexure models (Fig. 2f) are obtained by applying the FD method to Eq. (7). Before applying the FD method, all the data sets were mirror extended to be 9 times of their original size to reduce the computation errors caused by boundary condition, and the extended boundaries were removed after all the calculation processes were completed. The Moho interface is then used to obtain the forward Bouguer gravity anomaly (Fig. 3), with the relevant parameters listed in Table 1. The Moho inherits high-frequency information from the initial subsurface. However, 

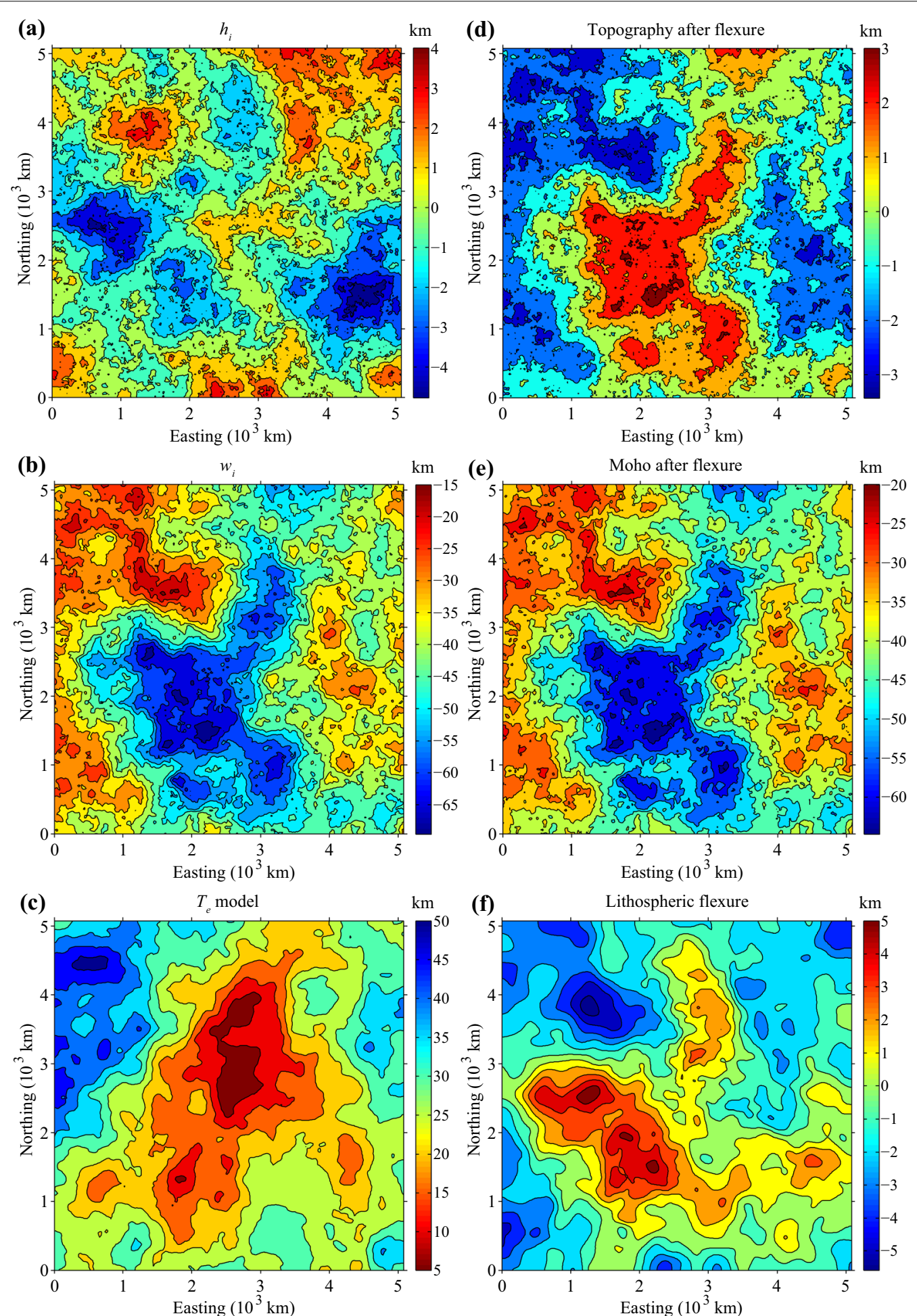

Fig. 2 a Initial surface $\left(h_{i}\right)$, b initial subsurface $\left(w_{i}\right), \mathbf{c} T_{e}$ model, $\mathbf{d}$ topography after flexure, e Moho after flexure, and $\mathbf{f}$ lithosphere flexure 


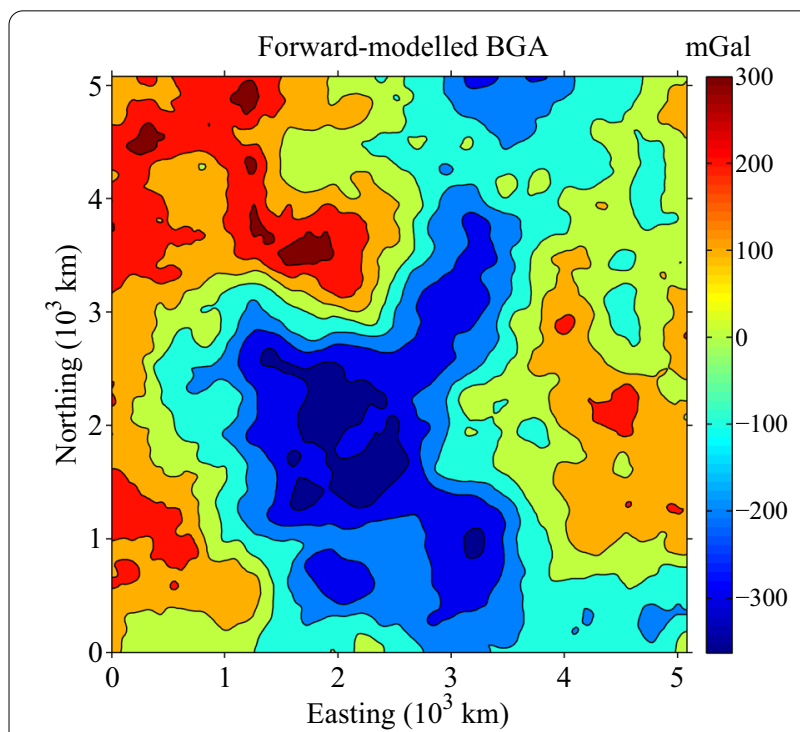

Fig. 3 Forward-modelled Bouguer gravity anomaly

the modelled Bouguer gravity anomaly may suffer from signal degradation due to upward continuation of the signal since the observation surface is much higher than the Moho interface, resulting in attenuation of this highfrequency information.

\section{Effect of $T_{e}$ errors}

The fan wavelet coherence method is employed to invert for $T_{e}$ (Fig. 4a) using the generated surface topography, Moho topography and forward-modelled Bouguer anomaly grids, and to calculate its associated errors (Fig. 4b). Note that, all the grids of errors are calculated by subtracting the forward-modelled grids from the inverted grids. This $T_{e}$ inversion recovers well the main $T_{e}$ features in the $T_{e}$ model. The errors are randomly distributed across the entire map, but the trend of the local errors is consistent with the $T_{e}$ gradient belts. This consistency is due mainly to the resolution of the transition wavelets, as well as two other adverse factors: (1) the decoupling assumption and (2) the assumption of uniform $T_{e}$ in the loading equations (Kirby and Swain 2008).

We then used the generated topography, Moho topography and inverted $T_{e}$ grids to estimate (Eq. (7)) the lithospheric flexure (Fig. 5a) and the associated errors (Fig. 5b). The long-wavelength component of the two flexure maps is basically the same (Figs. $2 \mathrm{f}$ and $5 \mathrm{a}$ ), and the amplitudes of the flexure errors (Fig. 5b) are up to one order of magnitude smaller than the $T_{e}$ errors (Fig. 4b). The $T_{e}$ error-induced flexure errors exhibit a rippling pattern due to the deflection of a higher $T_{e}$ plate possessing a lower amplitude and slower amplitude decay rate (see Fig. 6), although such a rippling pattern is truncated and/ or deformed by the attitudes of $T_{e}$ and total load. Furthermore, the range of the rippling pattern is affected by the $T_{e}$ values and load amplitude, although it has a higher correlation with the $T_{e}$ values in this synthetic modelling study, as the rippling pattern is obviously broader in the high $T_{e}$ regions.

To further explore the relation between the flexure errors and the $T_{e}$ errors, we simulated another data sets with a new $T_{e}$ model, who possesses an opposite numerical distribution pattern against the first $T_{e}$ model, and is notated as $T_{e}^{r}$. More exactly, $T_{e}^{r}=\operatorname{maximum}\left(T_{e}\right)+\operatorname{minimum}\left(T_{e}\right)-T_{e}$ (Fig. 7a). With the same procedure described above, we obtain the maps of lithospheric flexure with $T_{e}^{r}$ (Fig. 7b), inverted $T_{e}^{r}$ grid (Fig. 8a), $T_{e}^{r}$ errors due to the inversion (Fig. 8b),
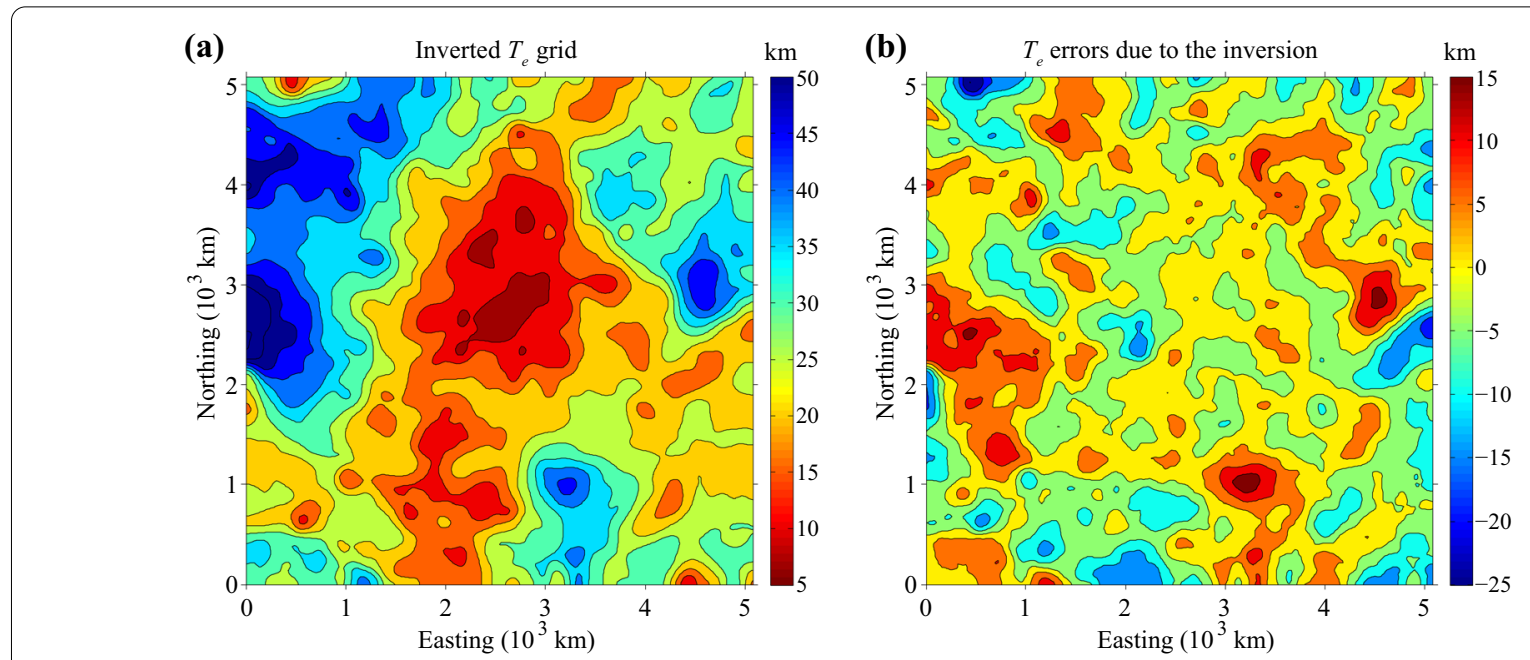

Fig. 4 a Inverted $T_{e}$ grid. $\mathbf{b} T_{e}$ errors due to the inversion 

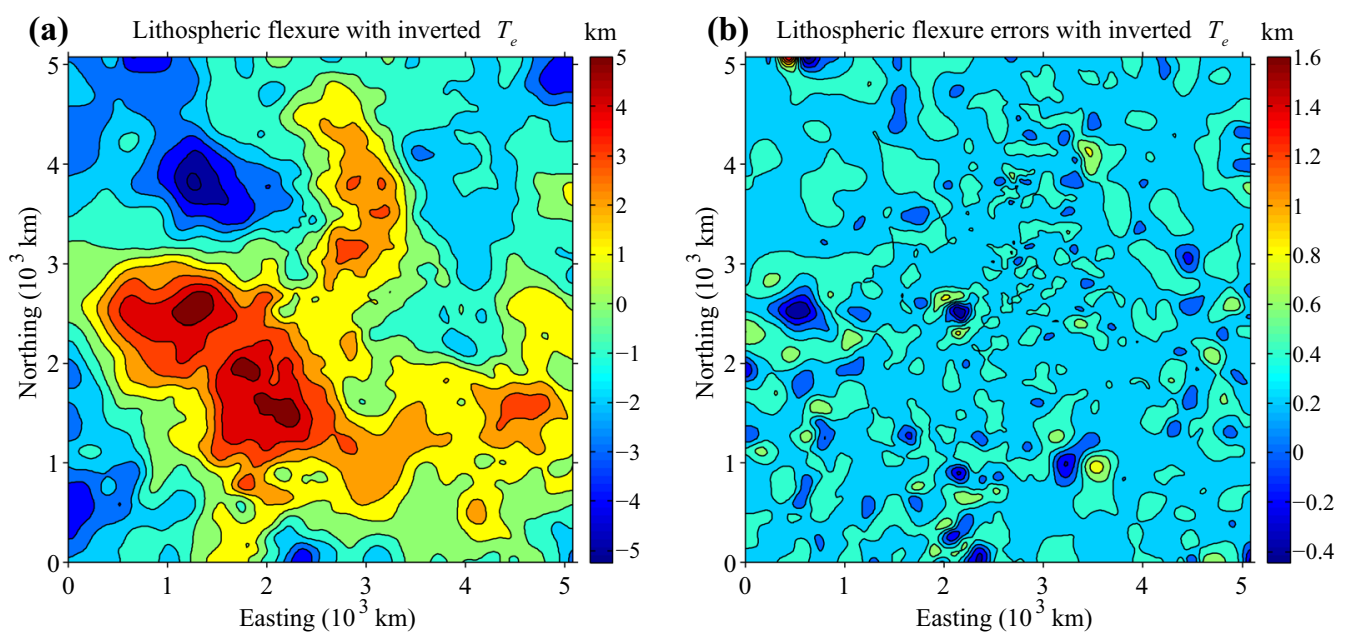

Fig. 5 a Lithospheric flexure using the inverted $T_{e}$ grid. $\mathbf{b}$ Lithospheric flexure errors for the model inversion using the inverted $T_{e}$ grid

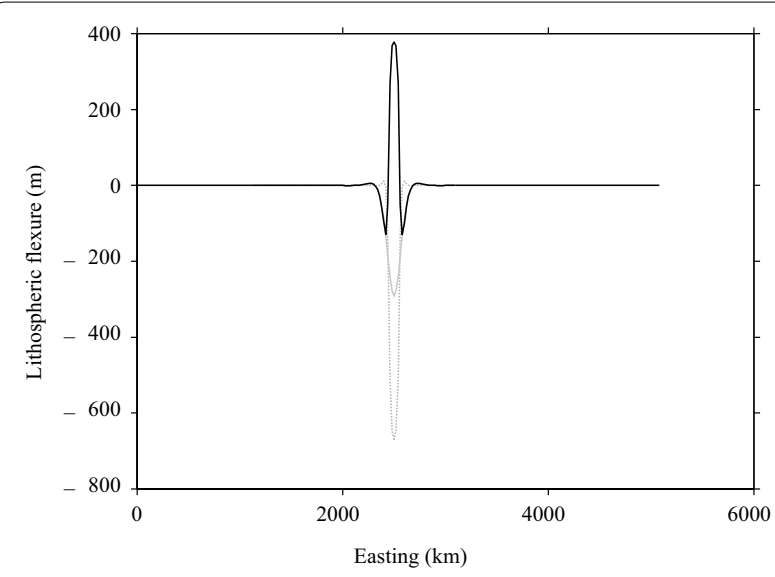

Fig. 6 Cross sections of the lithospheric flexure of uniform $T_{e}$ plates to a cuboid loading. The centre of the cuboid is placed at $(2500,2500)$ $\mathrm{km}$, with height of $1 \mathrm{~km}$, both length and width of $80 \mathrm{~km}$, density of $\rho_{c}$. The grey solid line is for a $T_{e}=25 \mathrm{~km}$ plate, the grey dotted line is for a $T_{e}=5 \mathrm{~km}$ plate and the black solid line is calculated by the grey solid curve minus the grey dotted curve

lithospheric flexure using the inverted $T_{e}^{r}$ grid (Fig. 9a) and lithospheric flexure errors for the model inversion using the inverted $T_{e}^{r}$ grid (Fig. 9b).

The high $T_{e}$ region is concentrated in the central part of the $T_{e}^{r}$ grid (Fig. 7a), this enhances the resistance of the central area to the applied loads and make the lithospheric flexure in the corresponding areas smoother (Fig. 8b). The inverted $T_{e}^{r}$ grid still reflects well the long wavelength part of the $T_{e}^{r}$ model, with the errors due to the inversion (Fig. 8b) much more concentrated at the central area. However, the consistency of the $T_{e}^{r}$ errors and the $T_{e}^{r}$ gradient belts is obvious as before. Figure 9 is dominated by the lithospheric flexure errors of rippling pattern, as significant errors are always surrounded by a series of errors in opposite sign. Though the difference between $T_{e}$ and $T_{e}^{r}$ grids is great, the response of lithospheric flexure is quite similar.

\section{Effect of Moho errors}

Bouguer gravity anomaly reflects the long-wavelength Moho information. It follows that the short-wavelength component of the flexure-derived Moho will be the main source of error (Fig. 10b) when we use the Bouguer anomaly to invert for the Moho topography (Fig. 10a). Although the maximum Moho error is $6 \mathrm{~km}$, the Moho inversion yields reliable results as the root-mean-square error is only $0.91 \mathrm{~km}$. Furthermore, the even distribution of the Moho errors provides insights into how the Moho inversion errors impact the flexure errors.

We also used the generated topography, $T_{e}$ model and recovered (inverted) Moho topography to estimate (Eq. (7)) the lithospheric flexure (Fig. 11a) and the associated errors (Fig. 11b). A comparison of the Moho and flexure results yields the following findings. (1) The Moho inversion errors are distributed evenly across the entire region, whereas the main flexure errors occur in the low $T_{e}$ regions. (2) The Moho errors tend to induce flexure errors with similar magnitudes but opposite signs (see the white rectangles in Figs. 10b and 11b). (3) The plate still acts as a low-pass filter to the Moho disturbance, even in the low $T_{e}$ regions, with an increase in the intensity of filtering, where there is an increase in the $T_{e}$ values.

Although the flexure error in the low $T_{e}$ regions, e.g., oceanic lithosphere, is sensitive to the Moho disturbance, this method is still suitable for investigations of the oceanic lithosphere. The reference depth of the oceanic Moho is shallow, which may allow us to 

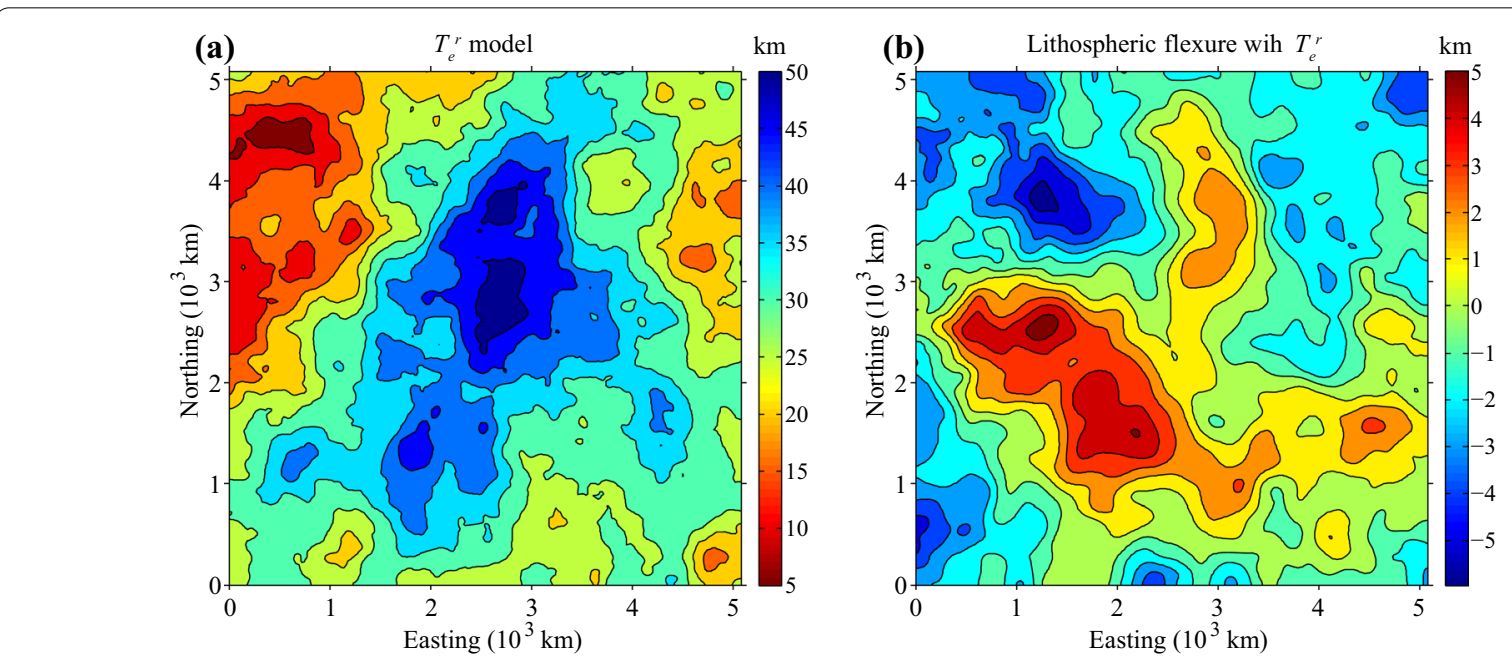

Fig. 7 a $T_{e}^{r}$ model. $\mathbf{b}$ Lithospheric flexure with $T_{e}^{r}$

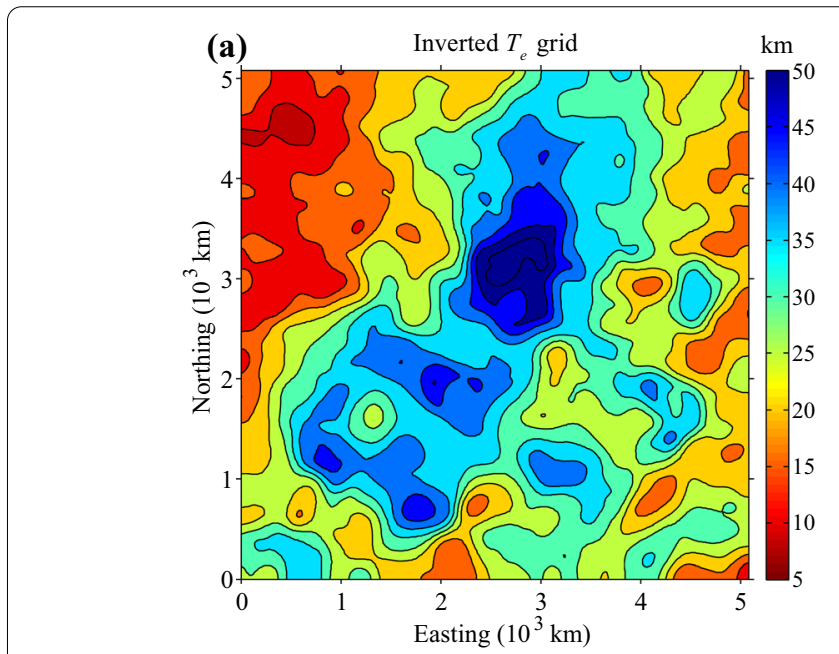

Fig. 8 a Inverted $T_{e}^{r}$ grid. $\mathbf{b} T_{e}^{r}$ errors due to the inversion

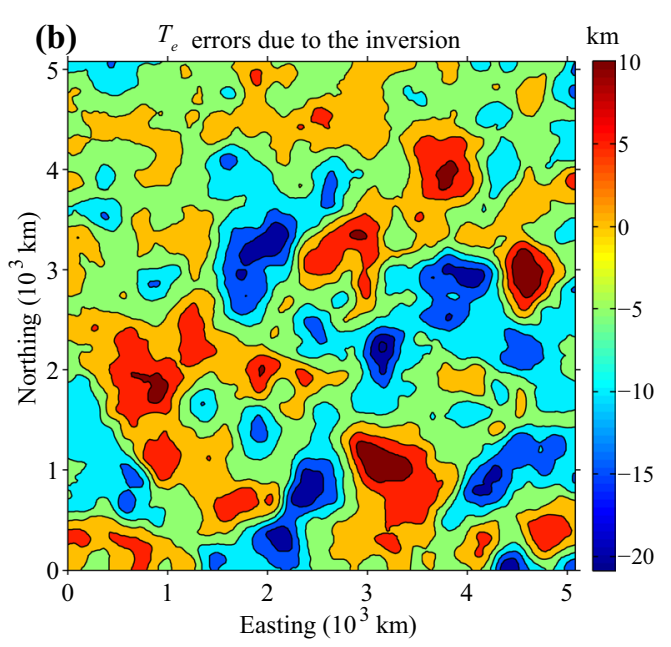

retain more short-wavelength information, such that more accurate inversion results can be obtained. In addition, the FD method-derived flexure is suited for Airy isostasy theory in regions, where $T_{e}$ reaches zero. However, we have to mention that, directly apply Airy isostasy theory in some low $T_{e}$ regions may greatly overestimate the lithospheric deformation amplitude. For example, take the extreme point whose coordinate is $(2.52,2.54)^{*} 10^{3} \mathrm{~km}$ in the lower white rectangle in Fig. 10b, the maximum Moho error reaches $4.258 \mathrm{~km}$ and we may expect a corresponding lithospheric flexure error of $-\left(\rho_{m}-\rho_{c}\right) /\left(\rho_{F}-\rho_{m}\right) * 4.258=-9.5805$ $\mathrm{km}$ with the Airy isostasy theory (the coefficient $-\left(\rho_{m}-\rho_{c}\right) /\left(\rho_{F}-\rho_{m}\right)$ comes from Eq. (7) by setting $D$ to be zero). However, this extreme point in Fig. 10b gets a value of $-2.520 \mathrm{~km}$, the amplitude is only $26.3 \%$ to the expected value from the Airy isostasy theory. This huge overestimation clarifies the significance of applying the FD method even in low $T_{e}$ regions when researching the vertical lithospheric/crustal deformation. 

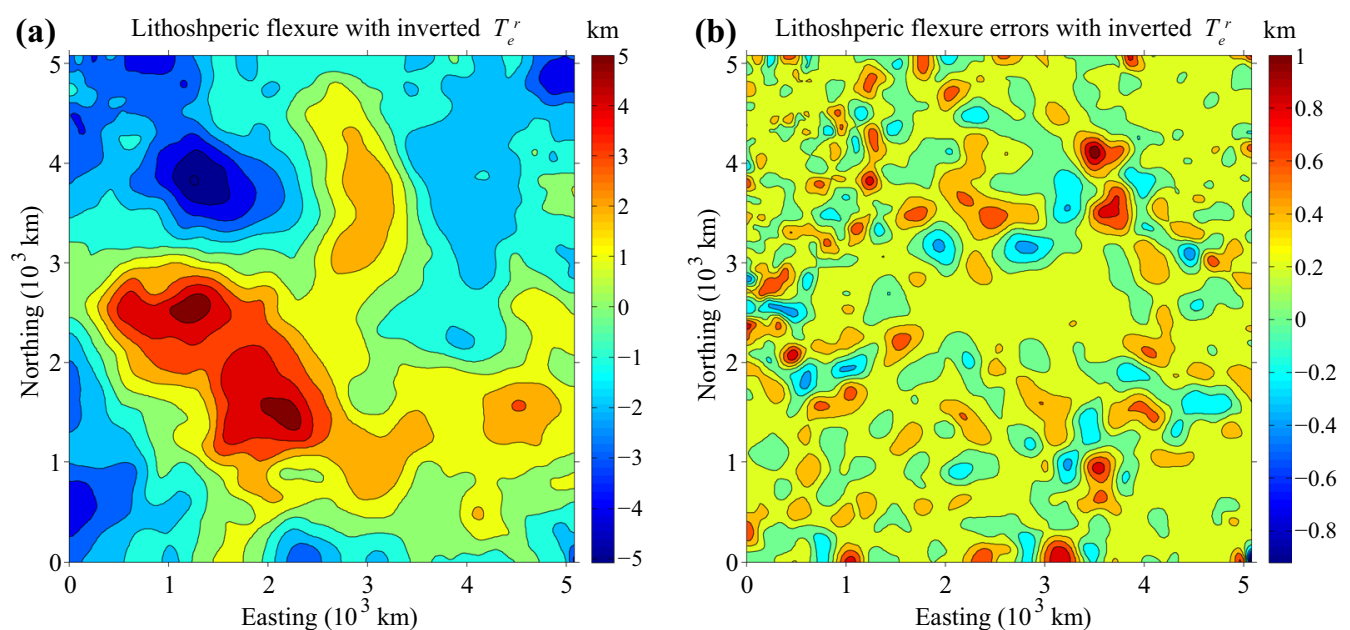

Fig. 9 a Lithospheric flexure using the inverted $T_{e}^{r}$ grid. b Lithospheric flexure errors for the model inversion using the inverted $T_{e}^{r}$ grid
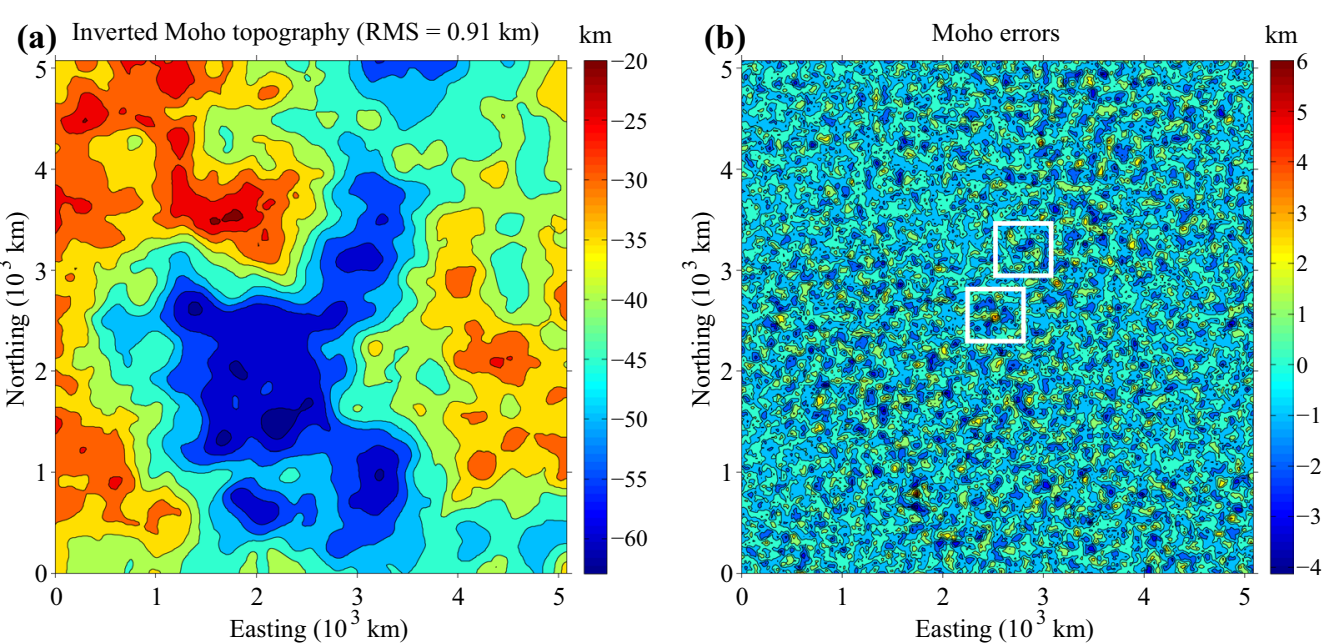

Fig. 10 a Inverted Moho topography with the forward-modelled Bouguer anomaly. b Moho errors

\section{Integrated effects of the $T_{e}$ and Moho errors}

Neither $T_{e}$ nor the Moho can be recovered with absolute accuracy using real data sets. We therefore investigated the integrated effects of the $T_{e}$ and Moho errors on the estimated lithospheric flexure errors to explicate the sources of the flexure errors. We used the generated topography, recovered $T_{e}$ and inverted Moho topography to invert (Eq. (7)) for the lithospheric flexure (Fig. 12a) and calculate their associated errors (Fig. 12b). The longwavelength component of the lithospheric flexure is still well recovered, indicating that the FD method is stable when an integrated disturbance is applied. The lithospheric flexure errors are dominated by the $T_{e}$ errors in the high $T_{e}$ regions (Figs. 5b, $11 \mathrm{~b}$ and $12 \mathrm{~b}$ ). Correspondingly, the flexure errors are dominated by the Moho errors in the low $T_{e}$ regions, although the amplitudes of the flexure errors have been somehow changed in the low $T_{e}$ regions (Figs. $11 \mathrm{~b}$ and $12 \mathrm{~b}$ ).

\section{Conclusions}

Here, we employed the classic lithospheric model with an applied external load at the surface and internal load at the Moho, and assumed that the compensation material was denser than the mantle material beneath the Moho, in an attempt to estimate lithospheric flexure. The resultant lithospheric model is closer to the actual lithospheric structure, with effective suppression of the overestimated lithospheric deflection predicted via linear theory, and conversion of the main lithospheric 

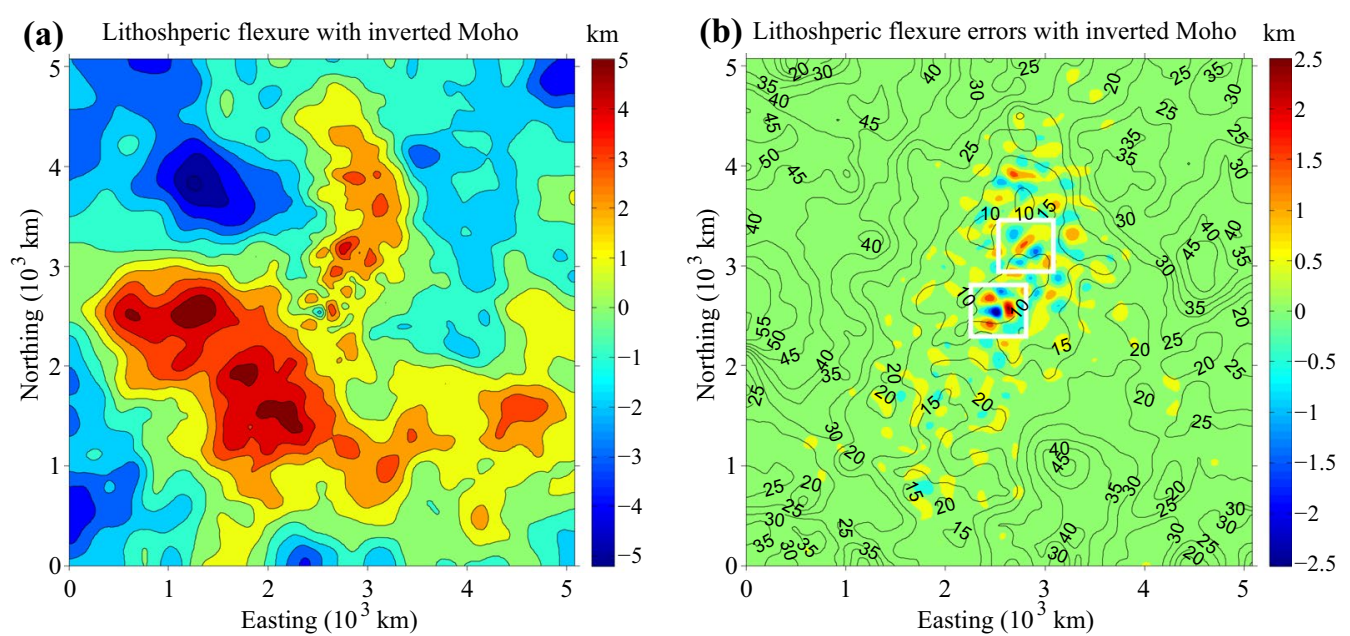

Fig. 11 a Lithospheric flexure using the inverted Moho values. b Base map is the lithospheric flexure errors for the model inversion using the inverted Moho values, the contours are from $T_{e}$ model
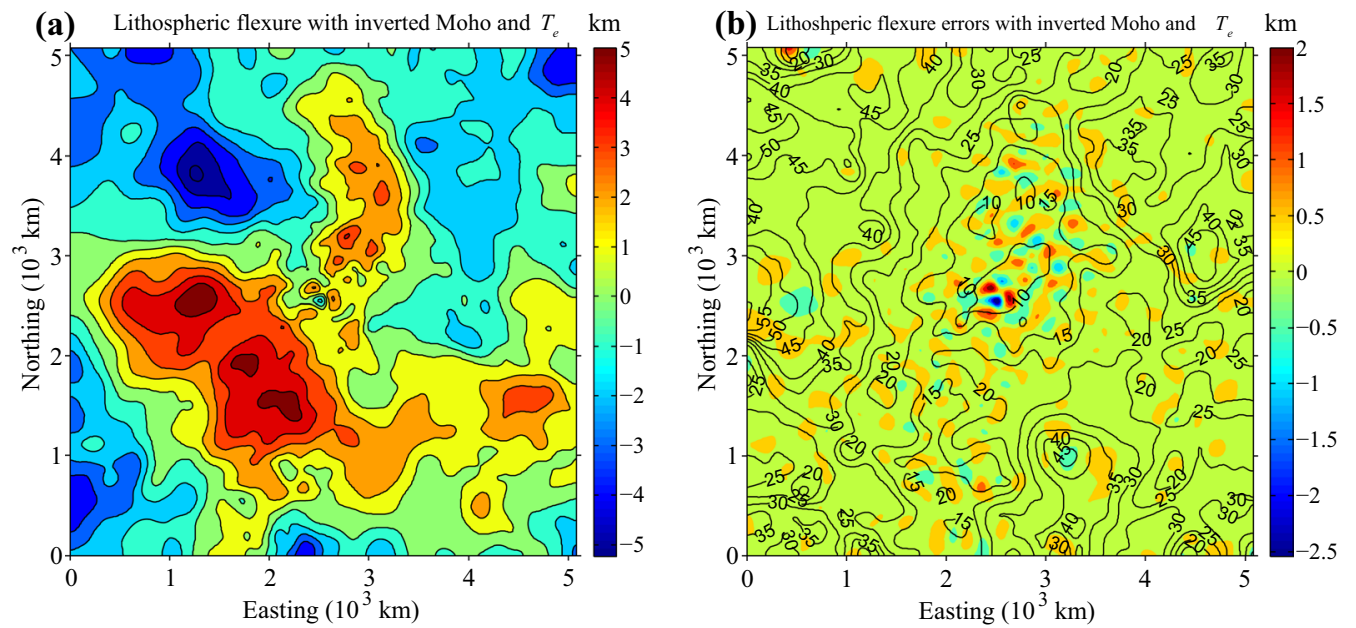

Fig. 12 a Lithospheric flexure using the inverted Moho and $T_{e}$ values. b Base map is the lithospheric flexure errors from the model inversion using the inverted Moho and $T_{e}$ values, the contours are from $T_{e}$ model

flexure inversion function (Eq. (6)) into a forward equation with a small Winkler foundation (Eq. (7)). This lithospheric model, which based on $T_{e}$ estimates from the fan wavelet coherence method and gravity-derived Moho topography, yields a finite-difference solution of the partial differential equation that recalibrates the lithospheric flexure with high accuracy. Our main conclusions are as follows:

1. The $T_{e}$ error-induced flexure errors exhibit a rippling pattern, and the rippling pattern is broader in high $T_{e}$ regions.
2. The Moho error-induced flexure errors mainly occur in the low $T_{e}$ regions, and applying Airy isostasy theory in low $T_{e}$ regions may still greatly overestimate the lithospheric deformation amplitude.

3. The flexure errors in the low and high $T_{e}$ regions are dominated by the Moho and $T_{e}$ errors, respectively.

\section{Appendix A: Finite-difference method}

The FD solution in Eq. (5) is mainly from Chen (2013), but we use the final loads instead of the initial loads on the right side of the equation. Equation (5) can be further simplified to 


$$
\begin{aligned}
& \nabla(D \nabla v)-(1-\sigma) \cdot\left\{\frac{\partial^{2} D}{\partial x^{2}} \frac{\partial^{2} v}{\partial y^{2}}-2 \frac{\partial^{2} D}{\partial x \partial y} \frac{\partial^{2} v}{\partial x \partial y}+\frac{\partial^{2} D}{\partial y^{2}} \frac{\partial^{2} v}{\partial x^{2}}\right\} \\
& =-\left(\rho_{c}-\rho_{f}\right) g h-\left(\rho_{m}-\rho_{c}\right) g w .
\end{aligned}
$$

The differential operations in Eq. (A1) are approximated using central difference operators. A schematic diagram of the central difference grid (Ghali et al. 1989) is shown in Fig. 13, whereby a square grid is adopted, such that $d x=d y$. The corresponding central difference operators for the first-order, second-order and Laplace differential operations are shown in Fig. 14.

The approximation to the differential operations is then undertaken with the central difference operators, followed by formula expansion and combination. The following coefficients of the indicated $v_{i, j}$ terms for an isotropic plate can then be obtained:

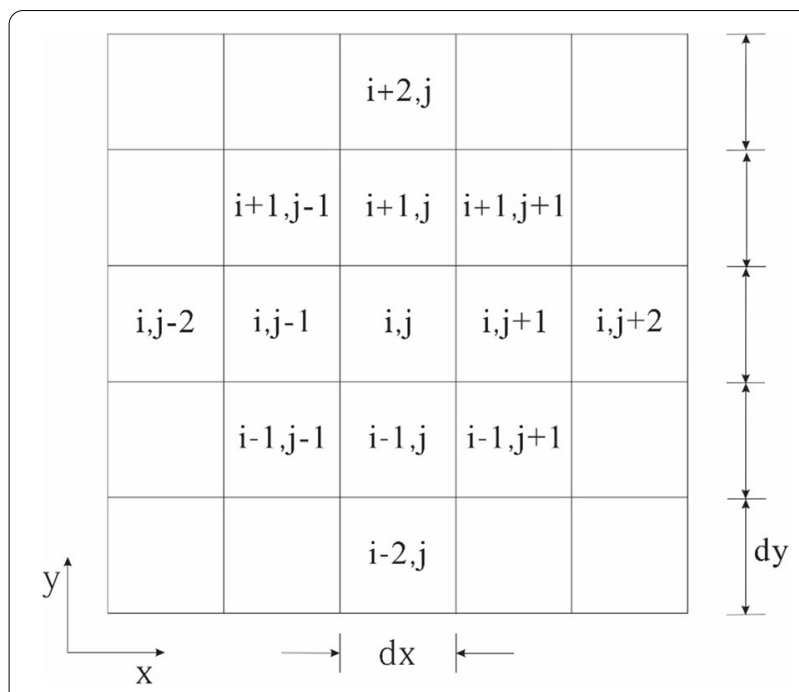

Fig. 13 Schematic diagram of the central difference grid

$$
\left\{\begin{array}{c}
v_{i, j}:(3-2 \sigma)\left(D_{i-1, j}+D_{i+1, j}+D_{i, j-1}+D_{i, j+1}\right)+8(1+\sigma) D_{i, j} \\
v_{i+1, j}:-2(1+\sigma) D_{i, j}-4 D_{i+1, j}-(1-\sigma)\left(D_{i, j-1}+D_{i, j+1}\right) \\
v_{i-1, j}:-2(1+\sigma) D_{i, j}-4 D_{i-1, j}-(1-\sigma)\left(D_{i, j-1}+D_{i, j+1}\right) \\
v_{i, j+1}:-2(1+\sigma) D_{i, j}-4 D_{i, j+1}-(1-\sigma)\left(D_{i-1, j}+D_{i+1, j}\right) \\
v_{i, j-1}:-2(1+\sigma) D_{i, j}-4 D_{i, j-1}-(1-\sigma)\left(D_{i-1, j}+D_{i+1, j}\right) \\
v_{i+1, j+1}: D_{i+1, j}+D_{i, j+1}+A \\
v_{i+1, j-1}: D_{i+1, j}+D_{i, j-1}-A \\
v_{i-1, j+1}: D_{i-1, j}+D_{i, j+1}-A \\
v_{i-1, j-1}: D_{i-1, j}+D_{i, j-1}+A \\
v_{i+2, j}: D_{i+1, j} \\
v_{i-2, j}: D_{i-1, j} \\
v_{i, j+2}: D_{i, j+1} \\
v_{i, j-2}: D_{i, j-1}
\end{array}\right.
$$

where $\quad A=\frac{1-\sigma}{8}\left(D_{i+1, j+1}-D_{i-1, j+1}-D_{i+1, j-1}+D_{i-1, j-1}\right)$, $d x=d y=\lambda$, and all of the coefficients must be divided by $\lambda^{4}$. For Eq. (7), only the first term in Eq. (A2) should be changed to

$$
\begin{aligned}
v_{i, j}: & (3-2 \sigma)\left(D_{i-1, j}+D_{i+1, j}+D_{i, j-1}+D_{i, j+1}\right) \\
& +8(1+\sigma) D_{i, j}+\left(\rho_{F}-\rho_{m}\right) g v \lambda^{4} .
\end{aligned}
$$

The data sets of the study area can be meshed into $\mathrm{M} \times \mathrm{N}$ grids, and $\mathrm{M} \times \mathrm{N}$ deflection values need to be calculated. Linear algebraic equations that incorporate the coefficients in Eq. (A3) can be used to calculate the deflection values as follows:

$$
R \vec{v}=-\left(\rho_{\mathrm{c}}-\rho_{\mathrm{f}}\right) g \vec{h}-\left(\rho_{\mathrm{m}}-\rho_{\mathrm{c}}\right) g \vec{w},
$$

where $\vec{v}$ is the deflection vector (a column vector with $\mathrm{M} \times \mathrm{N}$ rows), $\mathrm{R}$ is the difference coefficient matrix (a matrix with $\mathrm{M} \times \mathrm{N}$ columns and $\mathrm{M} \times \mathrm{N}$ rows), and $\vec{h}$ and $\vec{w}$ are the final surface and subsurface topography vectors (column vectors with $\mathrm{M} \times \mathrm{N}$ rows), respectively. We employed periodic boundary conditions during the calculations, and 24 kinds of boundary conditions that should be considered (Eq. A2 and Fig. 13). Furthermore, compression of the sparse matrix $\mathrm{R}$ is recommended, since it contains very few nonzero elements. 


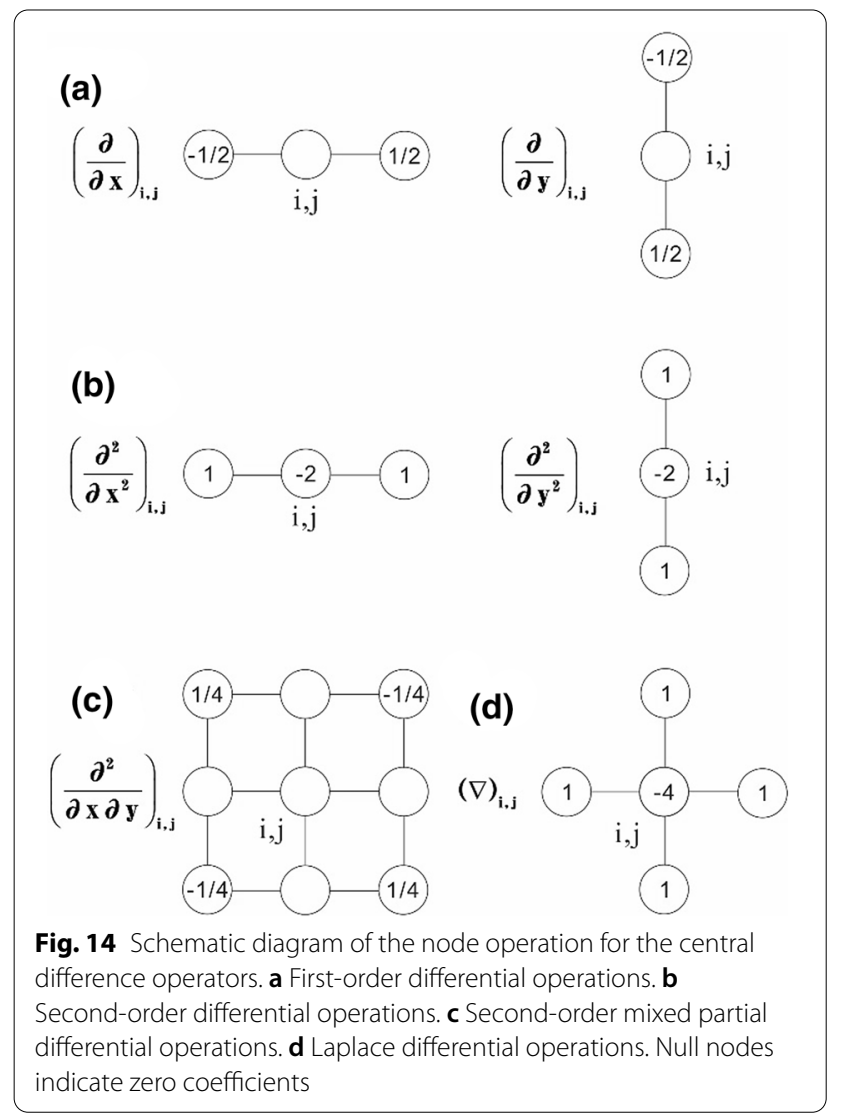

\section{Acknowledgements}

Not applicable.

\section{Authors' contributions}

MX processed and interpreted the data, produced the figures and wrote the main manuscript text. ZW assisted in the gravity inversion. FJ assisted in the application of the fan wavelet coherence method. AR, CL and JG contributed to the Lithospheric model discussion and manuscript revisions. All authors read and approved the final manuscript.

\section{Funding}

This work is supported by the Second Institute of Oceanography, Ministry of Natural Resources (Grant No. JT1601), the National Natural Science Foundation of China (Grant Nos. 42076078, 42076047, 41676037, 91858213, 41776057, and 41761134051), the National Program on Global Change and Air Sea Interaction (Grant No. GASI-GEOGE-05) and the Institute of Crustal Dynamics, China Earthquake Administration (Grant No. ZDJ2019-30).

\section{Availability of data and materials}

The data sets that were used, analysed and produced during the current study are available from the corresponding author upon reasonable request.

\section{Declarations}

\section{Competing interests}

The authors declare that they have no competing interests.

\section{Author details}

${ }^{1}$ School of Earth Sciences, Zhejiang University, Hangzhou 310007, China. ${ }^{2}$ Department of Marine Sciences, Zhejiang University, Zhoushan 316021, China. ${ }^{3}$ Key Laboratory of Submarine Geosciences, SOA \& Second Institute of Oceanography, MNR, No.36 Baochubei Road, Hangzhou 310012, China. ${ }^{4}$ National Institute of Natural Hazards, MEMA, No.1 Anningzhuang Road, Beijing 100085, China. ${ }^{5}$ Hainan Institute, Zhejiang University, Sanya 572025, China. ${ }^{6}$ Laboratory for Marine Mineral Resources, Qingdao National Laboratory for Marine Science and Technology, Qingdao 266237, China.

Received: 29 April 2021 Accepted: 13 August 2021

Published online: 27 August 2021

\section{References}

Bai Y, Williams SE, Müller RD, Liu Z, Hosseinpour M (2014) Mapping crustal thickness using marine gravity data: methods and uncertainties. Geophysics 79(2):G27-G36. https://doi.org/10.1190/geo2013-0270.1

Banks RJ, Francis SC, Hipkin RG (2001) Effects of loads in the upper crust on estimates of the elastic thickness of the lithosphere. Geophys J Int 145:291-299. https://doi.org/10.1046/j.0956-540x.2001.01380.x

Braitenberg C, Ebbing J, Gotze H-J (2002) Inverse modelling of elastic thickness by convolution method - the eastern Alps as a case example. Earth Planet Sci Lett 202:387-404. https://doi.org/10.1016/S0012-821X(02) 00793-8

Burov EB, Diament M (1992) Flexure of the continental lithosphere with multilayered rheology. Geophys J Int 109:449-468. https://doi.org/10.1111/j. 1365-246X.1992.tb00107.x

Chappell AR, Kusznir N (2008) Three-dimensional gravity inversion for Moho depth at rifted continental margins incorporating a lithosphere thermal gravity anomaly correction. Geophys J Int 174:1-13. https://doi.org/10. 1111/j.1365-246X.2008.03803.x

Chen B (2013) The effective elastic thickness over China and surroundings and its lithosphere dynamic implication, Doctoral thesis, China University of Geosciences, Wuhan. (in Chinese)

Chen B, Kaban MK, El Khrepy S, Al-Arifi N (2015) Effective elastic thickness of the Arabian plate: weak shield versus strong platform. Geophys Res Lett 42:3298-3304. https://doi.org/10.1002/2015GL063725

Dorman LM, Lewis BTR (1970) Experimental isostasy: 1. Theory of the determination of the Earth's isostatic response to a concentrated load. J Geophys Res 75:3357-3365. https://doi.org/10.1029/JB075i017p03357

Dorman LM, Lewis BTR (1972) Experimental isostasy: 3. Inversion of the isostatic Green function and lateral density changes. J Geophys Res 77:3068-3077. https://doi.org/10.1029/JB077i017p03068

Forsyth DW (1985) Subsurface loading and estimates of the flexural rigidity of continental lithosphere. J Geophys Res 90:12623-12632. https://doi.org/ 10.1029/JB090iB14p12623

Ghali A, Neville AM, Brown TG (1989) Structural analysis: a unified classical and matrix approach. Chapman and Hall, New York, p 870

Huang M, Thambiratnam D (2001) Deflection response of plate on Winkler foundation to moving accelerated loads. Eng Struct 23:1134-1141. https://doi.org/10.1016/s0141-0296(01)00004-9

Ji F, Gao J, Li F, Shen Z, Zhang Q, Li Y (2017) Variations of the effective elastic thickness over the Ross Sea and Transantarctic Mountains and implications for their structure and tectonics. Tectonophysics 717:127-138. https://doi.org/10.1016/j.tecto.2017.07.011

Ji F, Li F, Gao J-Y, Zhang Q, Hao W-F (2018) 3-D density structure of the Ross Sea basins, West Antarctica from constrained gravity inversion and their tectonic implications. Geophys J Int 215:1241-1256. https://doi.org/10. 1093/gji/ggy343

Ji F, Zhang Q, Zhou X, Bai Y, Li Y (2020) Effective elastic thickness of Zealandia and its implications for lithospheric deformation. Gondwana Res 86:46-59. https://doi.org/10.1016/j.gr.2020.05.008

Kaban MK, Stolk W, Tesauro M, El Khrepy S, Al-Arifi N, Beekman F, Cloetingh SAPL (2016) 3D density model of the upper mantle of Asia based on 
inversion of gravity and seismic tomography data. Geochem Geophys Geosyst 17:4457-4477. https://doi.org/10.1002/2016GC006458

Kalnins LM, Watts AB (2009) Spatial variations in effective elastic thickness in the Western Pacific Ocean and their implications for Mesozoic volcanism. Earth Planet Sci Lett 286:89-100. https://doi.org/10.1016/j.epsl.2009.06. 018

Kirby JF, Swain CJ (2004) Global and local isostatic coherence from the wavelet transform. Geophys Res Lett 31:L24608. https://doi.org/10.1029/2004G L021569

Kirby JF (2005) Which wavelet best reproduces the Fourier power spectrum? Comput Geosci 31:846-864. https://doi.org/10.1016/j.cageo.2005.01.014

Kirby JF, Swain CJ (2006) Mapping the mechanical anisotropy of the lithosphere using a 2D wavelet coherence, and its application to Australia. Phys Earth Planet Inter 158:122-138. https://doi.org/10.1016/j.pepi.2006. 03.022

Kirby JF, Swain CJ (2008) An accuracy assessment of the fan wavelet coherence method for elastic thickness estimation. Geochem Geophys Geosyst 9:Q03022. https://doi.org/10.1029/2007GC001773

Kirby JF, Swain CJ (2009) A reassessment of spectral Te estimation in continental interiors: The case of North America. J Geophys Res Solid Earth 114:B08401. https://doi.org/10.1029/2009JB006356

Kirby JF, Swain CJ (2011) Improving the spatial resolution of effective elastic thickness estimation with the fan wavelet transform. Comput Geosci 37:1345-1354. https://doi.org/10.1016/j.cageo.2010.10.008

Kirby JF (2014) Estimation of the effective elastic thickness of the lithosphere using inverse spectral methods: the state of the art. Tectonophysics 631:87-116. https://doi.org/10.1016/j.tecto.2014.04.021

Lewis BTR, Dorman LM (1970a) Correction to paper by Brian T. R. Lewis and LeRoy M. Dorman "Experimental isostasy: 2 An isostatic model for the U.S.A. derived from gravity and topographic data."J Geophys Res 75:4482-4482. https://doi.org/10.1029/JB075i023p04482

Lewis BTR, Dorman LM (1970b) Experimental isostasy: 2. An isostatic model for the U.S.A. derived from gravity and topographic data. J Geophys Res 75:3367-3386. https://doi.org/10.1029/JB075i017p03367

Lu Z, Li C-F, Zhu S, Audet P (2020) Effective elastic thickness over the Chinese mainland and surroundings estimated from a joint inversion of Bougue admittance and coherence. Phys Earth Planet Inter 301:106456. https:// doi.org/10.1016/.jpepi.2020.106456

Macario A, Malinverno A, Haxby WF (1995) On the robustness of elastic thickness estimates obtained using the coherence method. J Geophys Res Atmos 100:15163-15172. https://doi.org/10.1029/95JB00980

McKenzie D (2003) Estimating Te in the presence of internal loads. J Geophys Res Solid Earth 108(2438):B9. https://doi.org/10.1029/2002JB001766

McKenzie D, Fairhead D (1997) Estimates of the effective elastic thickness of the continental lithosphere from Bouguer and free air gravity anomalies. J Geophys Res Solid Earth 102(27523-27552):B12. https://doi.org/10. 1029/97JB02481

McNutt M (1980) Implications of regional gravity for state of stress in the Earth's crust and upper mantle. J Geophys Res Solid Earth 85:6377-6396. https://doi.org/10.1029/JB085iB1 1 p06377

Mofid M, Noroozi M (2009) A plate on winkler foundation with variable coefficient. Sci Iran Trans A 16:249-255

Oldenburg DW (1974) The inversion and interpretation of gravity anomalies. J Geophysics 39:526-536. https://doi.org/10.1190/1.1440444

Pérez-Gussinyé M, Lowry AR, Watts AB, Velicogna I (2004) On the recovery of effective elastic thickness using spectral methods: examples from synthetic data and from the Fennoscandian shield. J Geophys Res Solid Earth 109:B10409. https://doi.org/10.1029/2003JB002788

Pérez-Gussinyé M, Lowry A, Phipps Morgan J, Tassara A (2008) Effective elastic thickness variations along the Andean margin and their relationship to subduction geometry. Geochem Geophys Geosyst 9:Q02003. https://doi. org/10.1029/2007GC001786
Pérez-Gussinyé M, Metois M, Fernández M, Vergés J, Fullea J, Lowry AR (2009) Effective elastic thickness of Africa and its relationship to other proxies for lithospheric structure and surface tectonics. Earth Planet Sci Lett 287:152-167. https://doi.org/10.1016/j.epsl.2009.08.004

Peitgen H-O, Saupe D (eds) (1988) The science of fractal images. SpringerVerlag, New York

Press WH, Teukolsky SA, Vetterling WT, Flannery BP (1992) Numerical Recipes in Fortran 77. Cambridge University Press, Cambridge, U.K.

Ribe NM (1982) On the interpretation of frequency response functions for oceanic gravity and bathymetry. Geophys J Int 70:273-294. https://doi. org/10.1111/j.1365-246X.1982.tb04968.x

Sclater JG, Christie P (1980) Continental stretching: an explanation of the postmid-cretaceous subsidence of the Central North sea basin. J Geophys Res Solid Earth 85(6377-6396):B11. https://doi.org/10.1029/JB085iB11p06377

Simons FJ, Olhede SC (2013) Maximum-likelihood estimation of lithospheric flexural rigidity, initial-loading fraction and load correlation, under isotropy. Geophys J Int 193:1300-1342. https://doi.org/10.1093/gji/ggt056

Stark CP, Stewart J, Ebinger CJ (2003) Wavelet transform mapping of effective elastic thickness and plate loading: validation using synthetic data and application to the study of southern African tectonics. J Geophys Res Solid Earth 108:B12. https://doi.org/10.1029/2001JB000609

Timoshenko SP, Woinowsky-Krieger S (1959) Theory of plates and shells, 2nd edn. McGraw-Hill, New York

Watts AB, Burov EB (2003) Lithospheric strength and its relationship to the elastic and seismogenic layer thickness. Earth Planet Sci Lett 213:113131. https://doi.org/10.1016/S0012-821X(03)00289-9

Watts AB (2001) Isostasy and flexure of the lithosphere. Cambridge University Press, New York

Wu Z, Gao J, Ding W, Shen Z, Zhang T, Yang C (2017) The Moho depth of the South China Sea basin from three-dimensional gravity inversion with constraint points and its characteristics. Chin J Geophys 60:368-383. https://doi.org/10.1002/cjg2.30053

Zhang F, Lin J, Zhan W (2014) Variations in oceanic plate bending along the Mariana trench. Earth Planet Sci Lett 401:206-214. https://doi.org/10. 1016/.j.epsl.2014.05.032

Zhang F, Lin J, Zhou Z (2019a) Flexural bending curvature and yield zone of subducting plates. Int Geol Rev. https://doi.org/10.1080/00206814.2019. 1671237

Zhang F, Lin J, Zhou Z (2019b) Intra-trench variations in flexural bending of the subducting Pacific Plate along the Tonga-Kermadec Trench. Acta Oceanol Sin 38:81-90. https://doi.org/10.1007/s13131-019-1493-4

Zhang F, Lin J, Zhou Z, Yang H, Zhan W (2018a) Intra- and intertrench variations in flexural bending of the Manila, Mariana and global trenches: implications on plate weakening in controlling trench dynamics. Geophys J Int 212:1429-1449. https://doi.org/10.1093/gji/ggx488

Zhang J, Sun Z, Xu M, Yang H, Zhang Y, Li F (2018b) Lithospheric 3-D flexural modelling of subducted oceanic plate with variable effective elastic thickness along Manila Trench. Geophys J Int 215:2071-2092. https://doi. org/10.1093/gji/ggy393

Zhang J, Xu M, Sun Z (2018c) Lithospheric flexural modelling of the seaward and trenchward of the subducting oceanic plates. Int Geol Rev. https:// doi.org/10.1080/00206814.2018.1550729

Zhang J, Zhang F, Lin J, Yang H (2021) Yield failure of the subducting plate at the Mariana Trench. Tectonophysics 814:228944. https://doi.org/10. 1016/j.tecto.2021.228944

\section{Publisher's Note}

Springer Nature remains neutral with regard to jurisdictional claims in published maps and institutional affiliations. 